\title{
A Method to Determine the Sentence Structure of Animals and Insects
}

\author{
Robert William Bonner \\ Independent Researcher, Englewood, USA \\ Email: rbonner1@msudenver.edu
}

How to cite this paper: Bonner, R. W. (2022). A Method to Determine the Sentence Structure of Animals and Insects. Open Journal of Modern Linguistics, 12, 68-70.

https://doi.org/10.4236/ojml.2022.121007

Received: February 3, 2022

Accepted: February 18, 2022

Published: February 21, 2022

Copyright $\odot 2022$ by author(s) and Scientific Research Publishing Inc. This work is licensed under the Creative Commons Attribution International License (CC BY 4.0).

http://creativecommons.org/licenses/by/4.0/

\begin{abstract}
A Conjunction Pitch [a] is a Word nested between Two other Words in a Three Word String; [ $\underline{\mathrm{i}(\mathrm{a})}$ ], [ $\underline{\mathrm{i}(\mathrm{x})}]$, [ $\underline{\mathrm{i}(\mathrm{b})}]$. A Neighboring Pitch $[b]$ are Words or Sounds on either side of a Conjunction Pitch. To determine or decipher the sentence structure of any life form, a Conjunction Pitch is cataloged along with a Neighboring Pitch when a Neighboring Pitch and Conjunction Pitch are observed occurring twice.
\end{abstract}

\section{Keywords}

Sentence Structure, Animals, Insects, Decryption

\section{Data \& Methods}

Although the variation and sophistication of language from species to species differ, the segue linking each species together is the distinction between Pitch from one or more vocal contributions; this suggests Animals and Insects are utilizing a hidden sentence structure. By analyzing the language of any species, a structure is achieved when a Conjunction Pitch differs from a Neighboring Pitch. If the species being analyzed makes no distinction between Conjunction Pitch and Neighboring Pitch, then the spacing between Pitches must be considered as its structure. The foundation of this research originates from the distinction between Pitch, Tone, Frequency and Spacing of vocal contributions from Animals and Insects. Assuming there is a sophistication to the native language of Animals and Insects, with the evidence of an inherent capacity to coordinate, an underlying code is discoverable. As such, applying basic mathematics to the critical thought process regarding this concept achieves Four Laws.

1) The First Law: A Conjunction Pitch $[\underline{\mathrm{i}(\mathrm{x})}]$ is either a Dictionary.com (2015). Noun [i(1)], Pronoun [i(2)], Adjective [i(3)], Verb [i(4)], Adverb [i(5)], 


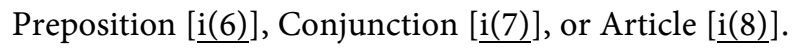

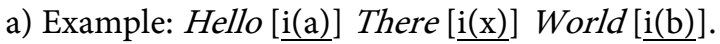

2) The Second Law: A Neighboring Pitch [(ㅏ)], [i(b)] cannot be a Conjunction Pitch $[\mathrm{i}(\mathrm{x})]$ unless it is a List.

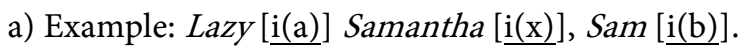

3) The Third Law: A List can begin or end with a Noun.

a) Example: Samantha [i(a)], $\operatorname{Sam}[\underline{\mathrm{i}(\mathrm{x})}]$, $\operatorname{Lazy}[\underline{\mathrm{i}(\mathrm{b})})$.

4) The Fourth Law: Pitch is equal to the following Eight Combinations of

$$
\begin{aligned}
& \text { Language; } \\
& \text { If }[\underline{\mathrm{i}(\mathrm{a})}]=\mathrm{a} \\
& \text { If }[\underline{\mathrm{i}(\mathrm{x})}]=\mathrm{x} \\
& \text { If }[\underline{\mathrm{i}(\mathrm{b})}]=\mathrm{b} \\
& \text { Then... } \\
& \text { 1) } \mathrm{a}>\mathrm{x}<\mathrm{b} \\
& \text { Or } \\
& \text { 2) } \mathrm{a}>\mathrm{x}>\mathrm{b} \\
& \text { Or } \\
& \text { 3) } \mathrm{a}<\mathrm{x}<\mathrm{b} \\
& \text { Or } \\
& \text { 4) } \mathrm{a}<\mathrm{x}>\mathrm{b} \\
& \text { Or } \\
& \text { 5) } \mathrm{a}=\mathrm{x}<\mathrm{b} \\
& \text { Or } \\
& \text { 6) } \mathrm{a}=\mathrm{x}>\mathrm{b} \\
& \text { Or } \\
& \text { 7) } \mathrm{a}<\mathrm{x}=\mathrm{b} \\
& \text { Or }
\end{aligned}
$$

8) $a>x=b$

The Method to determine the sentence structure and sophistication of any Animal or Insect language is achieved by comparing samples of vocal contributions, identifying one or more reoccurrences of a Neighboring Pitch to a Conjunction Pitch, and cataloging the results. For example; 1) Sam-Samantha-Lazy, 2) Bad-Samantha-Was, 3) Sam-Samantha-Funny. In this example, the Conjunction Pitch matches the Neighboring Pitch in both (1) and (3), which results in a positive catalog result.

1) Isolate any Three "Words" from any Species.

2) Isolate the First Word.

3) Isolate the Second Word.

4) Isolate the Third Word.

5) Define the Pitch of the Second Word in the String as a Conjunction Pitch $[\underline{\mathrm{i}(\mathrm{x})}]$.

6) Define the Pitch of the First Word in the String as a Neighboring Pitch [i(a)]. 
7) Define the Pitch of the Third Word in the String as a Neighboring Pitch [i(b)].

8) Compare the Conjunction Pitch $[\mathrm{i}(\mathrm{x})]$ in the Three-Word-String against a library of audio recordings from the same Species to identify a Neighboring Pitch.

9) Catalog each Neighboring Pitch as a Context to the Conjunction Pitch if the Neighboring Pitch occurs Twice.

a) Example: A and X in String A matches A and X in String C.

i) Catalog = No: $[\underline{\mathrm{i}(\mathrm{a} 123)}][\underline{\mathrm{i}(\mathrm{x} 1)}][\underline{\mathrm{i}(\mathrm{b} 456)}]=$ String A.

ii) Catalog = No: $[\underline{\underline{i}(\mathrm{a} 456)}][\underline{\mathrm{i}(\mathrm{x} 1)}][\underline{\mathrm{i}(\mathrm{b} 789)}]=$ String B.

iii) Catalog = Yes: $[\underline{\mathrm{i}(\mathrm{a} 123)}][\underline{\mathrm{i}(\mathrm{x} 1)}][\underline{\mathrm{i}(\mathrm{b} 1011)}]=$ String C.

\section{Conclusion}

The above Data \& Method enables the user to quickly decipher any language, without the definition of a Conjunction Pitch or Neighboring Pitch.

\section{Conflicts of Interest}

The author declares no conflicts of interest regarding the publication of this paper.

\section{References}

Dictionary.com (2015, October 7). The Eight Parts of Speech in English. https://www.dictionary.com/e/parts-of-speech/

\section{Glossary}

[a] Conjunction Pitch [i(x)]: The Pitch of a Word or Sound that is nestled between Two Words or Sounds in a string of Three Words or Sounds emitted from any life form.

[b] Neighboring Pitch [i(a)] [ [i(b)]: The Pitch of a Word or Sound that exists on either the beginning, the end, or both sides of a Conjunction Pitch emitted from any life form. 